\title{
Cenários de desenvolvimento para o Amapá 2020-2050
}

\author{
Marco Antonio Chagas \\ Programa de Pós-Graduação em Desenvolvimento Regional / Universidade Federal do Amapá (UNIFAP) \\ Antônio Sérgio Monteiro Filocreão \\ Programa de Pós-Graduação em Desenvolvimento Regional / Universidade Federal do Amapá (UNIFAP)
}

Recebido: 02/07/2019 Versão revisada (entregue): 29/10/2019 Aprovado: 06/11/2019

\begin{abstract}
Resumo
Este artigo descreve as atividades econômicas atualmente em curso no estado do Amapá e prospecta cenários de desenvolvimento para o período 2020-2050. Apresenta as atividades que mobilizam recursos naturais e o uso da terra, como mineração, hidrelétricas, petróleo e gás, agronegócio, áreas protegidas, além das condições da urbe amapaense. Em termos metodológicos, utiliza variáveis de empregabilidade, impactos, riscos e conflitos distributivos para prospectar três possíveis cenários: um trágico, um tradicional e um sustentável. Conclui-se que o Amapá segue tendência que caminha para uma realidade que se situa entre o trágico e o tradicional, embora não se descarte o cenário sustentável como utopia societária emancipatória. Contudo, este cenário somente é admitido epistemologicamente, em contexto de radical mudança política, distante do atual quadro dominado pela regulação social neoliberal.
\end{abstract}

Palavras-chave | Amapá; Amazônia; cenários; desenvolvimento; recursos naturais.

Código JEL | O21 Q32 R58

\section{Development scenarios for Amapá 2020-2050}

\begin{abstract}
This article describes the ongoing economic activities in the state of Amapá and draws development scenarios for the period 2020-2050. It exposes the activities that mobilize natural resources and comprise the use of land, such as mining enterprises, hydroelectric plants, gas and oil exploitation, agribusiness, protected areas as well as urban conditions. Methodologically, the article uses parameters of employability, impacts, risks and distributive conflicts in order to draw three possible scenarios: a tragic, a traditional and a sustainable one. It concludes that the state of Amapá undertakes a path leading to a reality that fits between the tragic and the traditional scenarios, what does not discard the sustainable scenario, which remains as an emancipatory social utopia. This scenario can only be epistemologically taken as possible within a context of radical political change, which is far from the current domination of the neoliberal social regulation.
\end{abstract}


Keywords | Amapá; Amazon; development; natural resources; scenarios.

JEL-Code | O21 Q32 R58

\section{Escenarios de desarrollo para Amapá 2020-2050}

\section{Resumen}

Este artículo describe las actividades económicas actualmente en curso en el estado de Amapá y la prospección de escenarios de desarrollo para el período 2020-2050. Presenta las actividades que movilizan recursos naturales y el uso de la tierra, como minería, hidroeléctricas, petróleo y gas, agronegocio, áreas protegidas, además de las condiciones de la ciudad de Amapa. En términos metodológicos, utiliza variables de empleabilidad, impactos, riesgos y conflictos distributivos para prospectar tres posibles escenarios: uno trágico, uno tradicional y un sostenible. Se concluye que el Amapá sigue la tendencia que camina hacia una realidad situada entre lo trágico y lo tradicional, pero sin descartar el escenario sostenible como utopía social emancipadora. Sin embargo, este escenario sólo es admitido epistemológicamente en contexto de cambio político radical, distante del actual cuadro dominado por la regulación social neoliberal.

Palabras clave | Amapá; Amazonia; escenarios; desarrollo; recursos naturales.

Codigo JEL | O21 Q32 R58

\section{Introdução}

Em 1943 o Amapá foi desmembrado do estado do Pará e se tornou Território Federal. Após 45 anos foi elevado à condição de estado pela Constituição de 1988. Apesar da conquista de sua autonomia político-administrativa, o estado mantém fortes vínculos de dependência com a União, a exemplo das transferências de recursos do Fundo de Participação dos Estados (FPE), do controle fundiário e mineral, da gestão de áreas protegidas, entre outras questões.

Referida condição de dependência do Amapá se desdobra em políticas de desconcentração e de descentralização tardia por parte da União, com implicações que perpassam por sobreposição de ações e consequentes conflitos de competências para gerir políticas públicas. Este quadro é agravado pelo intenso fluxo migratório intrarregional desassistido, principalmente de moradores das ilhas do Pará que se deslocam para o Amapá em busca de serviços básicos e de melhores condições de vida.

De fato, o Amapá acumula várias carências sociais e estruturais, com implicações negativas diretas em qualquer projeção de cenários, a ponto de galgar as piores 
posições entre os rankings de indicadores de mensuração do desenvolvimento. Por exemplo, no Índice dos Desafios da Gestão Estadual (IDGE), composto por 32 indicadores que aferem 10 áreas de resultados (educação, saúde, segurança, juventude, infraestrutura, desenvolvimento econômico, capital social, desenvolvimento social, condições de vida e institucional), o Amapá ocupa a última posição entre todos os estados da federação (MACROPLAN, 2017).

Não obstante ao pessimismo dos indicadores, esboçar cenários para o Amapá com horizonte temporal de 30 anos também impõe um duplo esforço epistêmico. O estado é referência de uma problematização que o divide entre os adeptos do desenvolvimentismo pela apropriação privada dos recursos naturais (exportação de commodities) - "os destruidores da natureza" - e os que defendem a preservação da biodiversidade (áreas protegidas) - "os protetores da natureza". Como superar essa dicotomia? Ou de fato existe uma linha abissal instransponível?

Nesse espectro, e a considerar a possibilidade de um conhecimento pós-dualista, o objetivo deste artigo é descrever as principais tendências de desenvolvimento para o Amapá e esboçar cenários prospectivos com vertentes analíticas que se desdobram entre posições das mais conservadoras até as filiadas ao discurso do desenvolvimento sustentável.

\section{Metodologia}

A metodologia utilizada seguiu procedimentos que, em primeiro lugar, possibilitaram identificar e analisar suscintamente as atividades econômicas que têm pulsado, direta e indiretamente, a agenda do desenvolvimento do Amapá. Esta etapa foi executada com base em consulta de diferentes fontes de informações, tais como séries históricas de exportação (minérios), de produção agrícola (soja), de licenciamento ambiental (hidrelétricas, petróleo e gás), de áreas protegidas (unidades de conservação), além da produção científica correlata.

Depois, foram selecionadas forças motrizes e variáveis críticas, como empregabilidade, impactos e riscos associados e conflitos distributivos. Esses três elementos são compreendidos como condições e incertezas que provavelmente terão maior influência sobre os cenários. A empregabilidade local é a principal força motriz da regulação do desenvolvimento, a considerar que o Amapá apresenta a maior taxa de desemprego do país. Os impactos e riscos são consequências que podem ameaçar a sociobiodiversidade e os conflitos distributivos são resultados da tensão entre o desenvolvimento e o meio ambiente.

Por último, foram projetados três possíveis cenários: trágico, tradicional e sustentável. Tais projeções procuraram se alicerçar também em saberes e experiências empíricas dos autores como participantes diretos da administração pública do Amapá e como pesquisadores das áreas de desenvolvimento e meio 
ambiente, respeitadas as orientações metodológicas de projeção de cenários sintetizadas por Costa e Nascimento (2007).

Particularidades da questão urbana amapaense foram inseridas como tema transversal aos diferentes cenários propostos. O propósito é identificar possíveis conexões da urbe com as variáveis analisadas, e, dessa forma, aferir percepções negligenciadas em estudos prospectivos, como no caso das relações sinérgicas desenvolvimentistas que se moldam em torno da visão de modernidade urbana construída sem considerar atributos sociais e ecológicos regionais conexos.

Reconhece-se, entretanto, a existência de alternativas de cenários de desenvolvimento para o Amapá, presentes em modos de vida e saberes de populações tradicionais (indígenas, ribeirinhos, quilombolas, campesinos e outras) com possibilidades de manifestações que não são acolhidas pelas categorias tratadas neste estudo e distante da regulação social neoliberal. Referidos cenários são emancipatórios e transitam em outras bases epistemológicas, em contraponto ao capitalismo, ao colonialismo e ao patriarcado (SANTOS; MENESES, 2010).

\section{Referencial Teórico}

Existe produção acadêmica que tem analisado os modelos de desenvolvimento com ênfase em abordagens que permitem contextualizar as diferentes formas de apropriação dos recursos naturais pelo capital global, como no caso das commodities, e, ao mesmo tempo, alertam reflexivamente para as destruidoras transformações sociais que se moldam a partir de uma economia controlada e autorregulada pelo mercado (POLANYI, 2000).

As economias extrativas de regiões ricas em matérias-primas, a exemplo da Amazônia, também têm instigado pesquisadores na busca de modelos teóricointerpretativos que possam explicar o subdesenvolvimento regional. Um reconhecimento à parte é creditado à obra de Bunker (1988; 2003) quanto ao pensamento crítico sobre o discurso desenvolvimentista de modernização da Amazônia baseada em exportação de commodities e sua verticalização sem diversificação econômica, com filiações que se seguem em pesquisas aplicadas a dinâmicas locais/regionais que confirmam referida hipótese (MONTEIRO, 2003; COELHO; MONTEIRO, 2005; MONTEIRO; COELHO, 2007) ou a refutam (DRUMMOND, 2002; DRUMMOND; PEREIRA, 2007).

A crença de que a abundância de recursos naturais de determinada região é condição para se alcançar o desenvolvimento, independente de fatores externos e subjetividades endógenas, é pura ilusão. Se assim fosse, existiria diferença abissal em termos de indicadores de desenvolvimento entre o Amapá e o Acre, quando se considera comparativamente a disponibilidade de recursos naturais, em abundância no primeiro e escasso no segundo. 
Desenvolvimento é de certo um conceito multidimensional e polissêmico. Transita entre percepções econômicas, ilusórias, liberais, sustentáveis, com implicações desafiadoras em termo de mensuração do Produto Interno Bruto (PIB), passando pelo Índice de Desenvolvimento Humano (IDH), até outros índices que se multiplicam quanto à busca de uma síntese de determinada realidade, mas circunscritos ao que Veiga (2005, p. 2008) considera como "ressurreição do pensamento utópico".

É nesse contexto de visibilizar o futuro com base em indicadores que os cenários são projetados. De maneira didática, Godet e Durance (2011, p. 26) definem cenários como "um conjunto formado pela descrição, de forma coerente, de uma situação futura e de encaminhamentos que permitam passar da situação de origem para a situação futura". Os estudos de cenários recorrem, normalmente, a um conjunto de técnicas e processos de sistematização de informações e hipóteses para análise das probabilidades de comportamentos futuros, de organização e teste da criatividade e das percepções subjetivas.

Projeções de cenários também têm sido subjugadas como previsões futuristas, com altos níveis de incertezas e que, portanto, criam mais expectativas e frustrações do que alternativas realizáveis. Pressupostos externos e domésticos, descontinuidades institucionais, instabilidades políticas e mudanças de valores societais são algumas das inferências que aumentam as variáveis a serem consideradas nas fragilidades metodológicas de projeção de cenários (BUARQUE, 2003).

A área ambiental, por exemplo, tem feito uso de técnicas de cenários desde a década de 1970, quando da produção do estudo "Limites do Crescimento", contratado pelo Clube de Roma junto ao Massachusetts Institute of Technology (MIT). As mudanças climáticas e a perda da biodiversidade, temas dominantes da agenda ambiental contemporânea, se fazem compreender pela simulação de cenários.

No Brasil, a antiga Secretaria de Assuntos Estratégicos da Presidência da República (SAE/PR), berço do Zoneamento Ecológico-Econômico (ZEE), e o Centro de Gestão e Estudos Estratégicos do Ministério da Ciência e Tecnologia (CGEE/MCT) registram importantes contribuições na projeção de cenários, sobretudo para a Amazônia (BUARQUE, 2003; MARCIAL; GRUMBACH, 2008; BRASIL, 2001; 2009).

Estudos aplicados de cenários têm prospectado o potencial e riscos ambientais associados na Amazônia, como no caso dos inventários de bacias hidrográficas, das indicações de áreas prioritárias para conservação da biodiversidade, das taxas de desmatamento da floresta, das mudanças climáticas, entre outros.

Entretanto, a complexidade do território amazônico passou a ser sistematizada e melhor compreendida pelos cenários projetados pela geógrafa Bertha Becker. A "Revolução Beckeriana", aqui entendida como o legado da obra de Bertha Becker, tornou-se a principal referência de cenários para a região, desde 1995, com a 
Política Nacional Integrada para a Amazônia Legal, até 2006, quando da concepção do Plano Amazônia Sustentável (VIEIRA; TOLEDO; ROCHA; SANTOS JÚNIOR, 2014).

O Quadro 1 apresenta uma síntese das principais políticas de governo projetadas para o ordenamento territorial da Amazônia, com reconhecida contribuição de Bertha Becker. Especificidades do estado do Amapá são grifadas como expressão de seu antagonismo de vocação projetada.

\section{Quadro 1 - Políticas de governo para a Amazônia com contribuição de Bertha Becker}

\begin{tabular}{|l|l|}
\hline Documento - Ano & \multicolumn{1}{|c|}{ Síntese executiva com percepções sobre o Amapá } \\
\hline $\begin{array}{l}\text { Política Nacional } \\
\text { Integrada para a } \\
\text { Amazônia Legal - } \\
1995\end{array}$ & $\begin{array}{l}\text { Elaborado no governo Fernando Henrique Cardoso. Traz uma } \\
\text { vertente desenvolvimentista, assente em “superar um ecologismo } \\
\text { estritamente preservacionista, para assumir um ecologismo voltado } \\
\text { para o desenvolvimento". Propóe três diretrizes gerais: I - } \\
\text { Reorientação do Crescimento Econômico; II - Integração Interna e } \\
\text { Externa; III - Valorização Humana. }\end{array}$ \\
\hline $\begin{array}{l}\text { Plano Amazônia } \\
\text { Sustentável - 2006 }\end{array}$ & $\begin{array}{l}\text { Elaborado no governo Lula. O plano propõe cenários para o } \\
\text { desenvolvimento regional com base num novo recorte territorial: } \\
\text { Arco do Povoamento Adensado, Amazônia Central e Amazônia } \\
\text { macrorregião da Amazônia Central (microrregião Fronteira de Preservação. }\end{array}$ \\
\hline $\begin{array}{l}\text { Um projeto para a } \\
\text { Amazônia no século } \\
\text { 21: desafios e } \\
\text { contribuições - 2009 }\end{array}$ & $\begin{array}{l}\text { região pensada com e sem mata. Descreve processos e dinâmicas em } \\
\text { curso que projetam a Amazônia sem mata, mas com proposições de } \\
\text { intervenções favoráveis à reversão pela regularização fundiária, } \\
\text { zoneamento ecológico-econômico e organização produtiva. Cita a } \\
\text { implantação de um porto off-shore no Amapá para escoamento da bioprodução e } \\
\text { de produtos minerais manufaturados. }\end{array}$ \\
\hline
\end{tabular}

Fonte: Brasil (1995); Brasil (2006); Brasil (2009).

Na Política Nacional Integrada para a Amazônia Legal constam os primeiros exercícios de zoneamento para a região, com projeção de três zonas: produtivas, críticas e especiais. No Plano Amazônia Sustentável (PAS), o ordenamento territorial está entre as principais diretrizes para a promoção da regularização fundiária, da proteção dos ecossistemas e dos direitos das populações tradicionais, bem como para a melhor destinação das terras para a exploração produtiva. Por último, no documento "Um projeto para a Amazônia no século 21", a regularização fundiária e a implementação do zoneamento ecológico-econômico são apresentadas como os principais desafios da região. 
A contribuição de Berta Becker na projeção de cenários para a Amazônia é complementada por um vasto acervo de produção da autora no campo da geopolítica e da gestão ambiental-territorial amazônica, desde o entendimento conceitual de fronteira e da ocupação do espaço, presente em Becker, Miranda e Machado (1990), até o desafiador e negligenciado tema das imbricações sinergéticas entre a floresta e o espaço urbano amazônico (BECKER, 2013).

\section{Caracterização sintética da base de recursos naturais do Amapá}

O estado do Amapá apresenta um histórico de apropriação de recursos naturais, sobretudo minérios (manganês, caulim, cromita, ferro e ouro) e, mais recente, do potencial hídrico para geração de hidroeletricidade. Exploração off-shore de petróleo e gás no Amapá estão em fase de estudos de viabilidade ambiental e econômica (licenciamento ambiental e pesquisa).

São recorrentes as análises acadêmicas que incluem o Amapá como parte integrante de uma região periférica submetida a uma lógica econômica capitalista de fronteira (BECKER; STENNER, 2008; CASTRO, 2012), mas também como um território vocacionado para a sustentabilidade (CASTRO, 1998; MOULIN, 2000, CHAGAS, 2002; BRONDÍZIO, 2003; RUELLAN; CASTRO; MOULIN, 2007; CHAGAS, 2013).

A seguir são descritas as principais bases de recursos naturais sintrópicas que ancoram o debate sobre o desenvolvimento do Amapá, incluindo percepções que são negligenciadas pelo pensamento dominante do crescimento econômico, como no caso das áreas protegidas e suas conexões com o desenvolvimento sustentável (SACHS, 2004).

É importante destacar que as áreas protegidas traduzem muitos significados e conceitos híbridos, incluindo o seu valor de não uso ou de existência, quanto então prevalecem princípios que extrapolam a própria noção de Estado, como a ancestralidade dos direitos indígenas e da própria natureza. A inclusão das áreas protegidas neste tópico é para reforçar referidos princípios.

\section{Mineração}

No Século XIX a fronteira Amapá-Guiana esteve envolta em disputas territoriais por recursos minerais. Em 1901, a região mais ao Norte do Amapá, acima do rio Araguari, rica em depósitos de ouro, então reivindicada como colônia francesa, foi arbitrada internacionalmente em favor de sua incorporação ao território brasileiro. A região passou a integrar o estado do Pará até 1943, quando então foi desmembrada e elevada à categoria de Território Federal do Amapá. 
No ano de 1943 ocorreu no Amapá a descoberta das minas de manganês de Serra do Navio, fato este que, pela quantidade/qualidade das jazidas e condição estratégica do minério na economia global, marcou profundamente a geopolítica da região. Drummond e Pereira (2007), - autores da obra de maior fôlego sobre a mineração de manganês do Amapá, mina exaurida em 1998 após quase 50 anos de produção -, sustentam que a exploração mineral teve seus benefícios tributários condicionados a investimentos estrategicamente modestos, demonstrando falta de visão de futuro da administração pública da época quanto ao desenvolvimento autônomo do Amapá, principalmente em relação à infraestrutura do estado.

\begin{abstract}
Pelo que se sabe, a única peça de infraestrutura importante que o governo local ofereceu aos amapaenses a partir dos royalties de mineração (embora eles tenham sido insuficientes para completar a obra) foi a Usina Hidrelétrica Coaracy Nunes. Embora importante, uma usina de 60 MW é um ativo desenvolvimentista modesto para um período de 40 anos de royalties (DRUMMOND; PEREIRA, 2007, p. $373)$.
\end{abstract}

Estudos sobre a mineração na Amazônia desenvolvidos por Monteiro (2001), Enríquez (2008), Oliveira (2010) e Chagas (2013) contribuem para avaliar possíveis cenários de desenvolvimento que incluam a atividade de mineração na agenda de opções econômicas ou mesmo (des)considerem as lições apreendidas, como no caso da exploração de manganês na região de Serra do Navio.

Para Monteiro (2001), apenas a exportação de commodities minerais não gera desenvolvimento para as regiões extrativas. O autor se filia à tese do sociólogo Stephen Bunker para explicar as trocas desiguais de energia e matéria entre economias dominantemente extrativas e as de produção. Os países industrializados pilham as energias e matérias-primas (as ilhas de sintropia - estado de elevada ordem de um sistema) das regiões extrativas e as transformam, produzindo a ordem (desenvolvimento) nos países industrializados e a desordem material-social (entropia) nas regiões extrativas.

Enriquez (2008), Oliveira (2010) e Chagas (2013) reconhecem experiências exitosas de mineração na Amazônia, mas vinculam suas análises ao aproveitamento das rendas mineiras pelos governos e a possíveis acordos voluntários adicionais. Enríquez (2008, p. 365), ao avaliar o destino da Compensação Financeira pela Exploração de Recursos Minerais (CFEM) de municípios mineiros no Brasil, constatou que há forte associação entre a qualidade do gasto, a qualidade da governança e os indicadores socioeconômicos desses municípios.

A análise de indicadores de desenvolvimento sustentável (ambiental, social, econômico e institucional) de municípios do Amapá com extração mineral, 
realizada por Oliveira (2010), indicou baixa relação entre as rendas mineiras e o desenvolvimento desses municípios. O autor apontou como principal causa o despreparo do poder público (estadual e municipal) para lidar com as questões que envolvem o setor de mineração, os royalties e a sustentabilidade, demonstrando pouco aprendizado do estado com as experiências extrativas vivenciadas.

No que lhe concerne, Chagas (2013) se deteve a estudar possíveis conexões entre a mineração no Amapá, a gestão ambiental e os protocolos do setor pelo desenvolvimento sustentável. Entre os achados, o autor destacou que os protocolos pactuados globalmente pela sustentabilidade da mineração se mantêm distantes das operações locais, principalmente em regiões periféricas como o Amapá. Acordos voluntários, tratados em processos de livre negociação, apresentam resultados instigantes, como no caso dos fundos voluntários criados por empresas de mineração para apoiar projetos socioambientais nas regiões diretamente impactadas, sinaliza o autor.

Desde a garimpagem, quando da afirmação da fronteira Norte como território nacional, no começo do Século XX, até os dias atuais, quando se registram ciclos completos de extração mineral industrial, como no caso da mina de manganês de Serra do Navio, a mineração se faz presente na construção da história geopolítica do Amapá e deve continuar pautando a agenda econômica do desenvolvimento regional.

\section{Hidrelétricas}

Quanto à instalação de hidrelétricas no Amapá, registros dão conta que as bacias dos rios Araguari e Jari foram inventariadas e passaram a integrar a estratégia de aumento da produção energética nacional baseada na construção de médias centrais hidrelétricas com uso de tecnologias de baixo impacto (fio d'água). Os inventários realizados indicaram capacidade de geração de 602 Megawatts (MW) na bacia do rio Araguari e 1.360 MW na do rio Jari (BRASIL, 1999; EPE, 2010) (Tabela 1). 
Tabela 1 - Aproveitamentos hidrelétricos inventariados no Amapá

\begin{tabular}{l|c|l|c}
\hline \multicolumn{2}{c|}{ Bacia do Rio Araguari } & \multicolumn{2}{c}{ Bacia do Rio Jari } \\
\hline Aproveitamentos & Potência (MW) & Aproveitamentos & Potência (MW) \\
\hline Ferreira Gomes I & 153 & Açaipé B & 830 \\
\hline Coaracy Nunes II & 104 & Urucupatá & 290 \\
\hline Cachoeira Caldeirão I & 134 & Carecuru & 240 \\
\cline { 1 - 2 } Bambu & 84 & Total & 1.360 \\
\cline { 1 - 2 } Porto da Serra I & 54 & & \\
\cline { 1 - 2 } Água Branca I & 73 & & \\
\cline { 1 - 2 } Total & 602 & &
\end{tabular}

Fonte: Brasil (1999); EPE (2010).

Os aproveitamentos hidrelétricos Ferreira Gomes e Cachoeira Caldeirão, no rio Araguari, e Santo Antônio, no rio Jari, foram leiloados em 2010 pela Agência Nacional de Energia Elétrica (ANEEL) como parte integrante do Programa de Aceleração do Crescimento (PAC). As três hidrelétricas encontram-se implantadas e em operação.

Em particular, a Hidrelétrica Coaracy Nunes (Paredão), construída em 1975 com participação dos royalties pagos pela exploração do manganês, possivelmente deverá ser inserida em alguma estratégia governamental de repotencialização e/ou privatização, considerando sua baixa geração de energia e a consequente inviabilidade econômica.

A implantação de hidrelétricas no Amapá tem de lidar com fortes restrições ambientais e conflitos sociais. Entretanto, a gestão do setor de energia demonstra intenso componente político e enunciados resgatados em documentos públicos indicam o interesse em explorar o potencial da região:

Está em desenvolvimento pelo Banco Interamericano de Desenvolvimento (BID) um estudo que visa à integração energética entre a Guiana, Guiana Francesa, Suriname e Brasil. O estudo tem o objetivo de mostrar a viabilidade da integração e permitir o aproveitamento do potencial energético inexplorado das Guianas e Suriname, que deve estar em torno de 6 GW (BRASIL, 2015, p. 75).

O inventário da Bacia do Rio Jari aponta a existência de aproveitamentos hidrelétricos que, mesmo considerando as restrições ambientais, podem despertar o interesse de empresas pela concessão e construção. Não se descarta, entretanto, políticas para edificação de Pequenas Centrais Hidrelétricas (PCHs), também 
inventariadas no Amapá, em complementação às já instaladas. Essas PCHs poderiam suprir o mercado de energia para o Norte do Amapá e Guiana Francesa.

\section{Petróleo e Gás}

A possibilidade de ocorrência de petróleo e gás na costa do Amapá não é um tema novo. Entretanto, os avanços das técnicas de pesquisa colocaram a ocorrência como uma condição de interesse de verificação de viabilidade comercial, principalmente diante de similaridades com áreas geológicas correlatas e próximas produtoras de petróleo e gás, como no caso da costa oeste africana e da vizinha Guiana Francesa.

Em 2013, a Agência Nacional de Petróleo, Gás Natural e Biocombustíveis (ANP) promoveu a $11^{a}$ rodada de licitação, contemplando blocos da bacia marítima da Foz do Amazonas, alguns destes localizados na costa amapaense (Figura 1). Um dos blocos licitados, o FZA-M-57, do Setor SFZA-AP1, localizado em mar territorial em projeção ao norte do município Oiapoque, recebeu o maior bônus de assinatura ${ }^{1}$, com valor de $\mathrm{R} \$ 345$ milhões ofertado pelo consórcio vencedor liderado pela empresa petrolífera francesa Total.

\footnotetext{
1 Corresponde ao valor pago pela concessionária vencedora de licitação de campos exploratórios, no ato da assinatura do contrato, com a finalidade de obter permissão para realizar suas atividades de pesquisa e exploração em determinada área (terrestre ou marítima). Seu valor mínimo é fixado pela Agência Nacional de Petróleo, Gás Natural e Biocombustíveis (ANP) em edital de licitação.
} 
Figura 1 - Blocos licitados na costa amapaense pela ANP para exploração de petróleo e gás

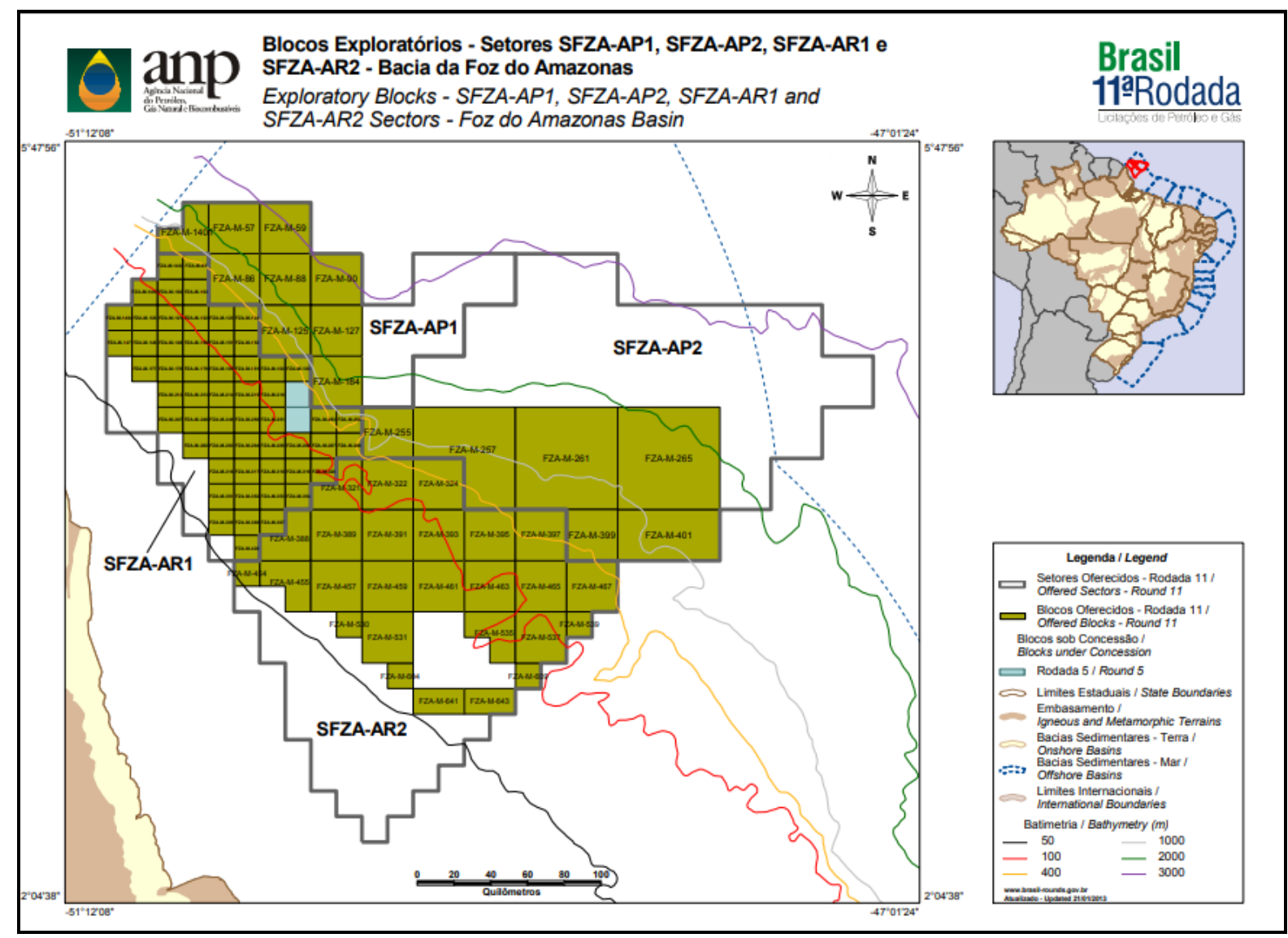

Fonte: ANP (2018).

Os blocos localizam-se distantes da linha de costa $(>100 \mathrm{~km})$, em águas ultraprofundas (>1.500 metros de lâmina d'água), nos limites da fronteira do Amapá com a Guiana Francesa. Nessa fase, as empresas concessionárias dos blocos pretendem realizar pesquisas para verificação de viabilidade comercial da ocorrência de petróleo e gás. A Tabela 2 apresenta os blocos exploratórios da Bacia da Foz do Amazonas licitados na costa do Amapá por empresa líder vencedora e quantidade de poços exploratórios a serem perfurados. 


\begin{tabular}{l|c|c}
$\begin{array}{l}\text { Tabela 2 - Blocos exploratórios da } \\
\text { empresa/exploração }\end{array}$ & costa amapaense por \\
\hline Empresa Líder & Blocos Exploratórios & $\begin{array}{c}\text { Quantidade de poços a serem } \\
\text { perfurados }\end{array}$ \\
\hline Total E\&P do Brasil & $\begin{array}{c}\text { FZA-M-57, FZA-M-86, FZA-M- } \\
\text { 88, FZA-M-125 e FZA-M-127 }\end{array}$ & 09 \\
\hline British Petroleum (BP) & FZA-M-59 & 02 \\
\hline Queiroz Galvão & FZA-M-90 & 01 \\
\hline
\end{tabular}

Fonte: AECOM do Brasil (2015a; 2015b; 2015c).

O licenciamento ambiental das pesquisas dos blocos licitados está arquivado no Instituto Brasileiro do Meio Ambiente e dos Recursos Naturais Renováveis (IBAMA), pelo não atendimento de pedido de estudos complementares para suprir lacunas identificadas nas audiências públicas e nas análises internas do órgão licenciador, incluindo impactos sobre um extenso recife de corais (Corais da Amazônia) que ocorre na área de influência direta dos blocos. Conflitos com pescadores da região e riscos às unidades de conservação costeira do Amapá têm também pautado questionamentos quanto à viabilidade ambiental da exploração de petróleo e gás na região.

O equacionamento de fatores econômicos e ambientais, como custos, tecnologias e riscos de produção em águas ultraprofundas (fatores climáticos adversos, grandes distâncias e profundidades), complexidade do licenciamento ambiental, presença de ecossistemas frágeis e legalmente protegidos, expectativas da população por geração de emprego e protocolos globais assumidos na $21^{\text {a }}$ Conferência da Partes (COP 21) constitui uma complexa agenda, não somente dos investidores do setor, mas também dos governos e, sobretudo, das populações locais.

\section{Cultivo de soja e agronegócio}

Atividade econômica recente no Amapá, o agronegócio tem na conversão do cerrado em monoculturas de grãos, sobretudo soja, sua mais expressiva forma de inserção de uma cultura exógena e potencializadora de conflitos socioambientais que perpassam pela posse irregular da terra, impactos sobre os ecossistemas e incertezas quanto às linkagens econômicas ${ }^{2}$ capazes de gerar benefícios equânimes locais.

\footnotetext{
${ }^{2}$ Linkagens econômicas - conceito desenvolvido pelo economista Albert Hirschman para analisar os efeitos de projetos sobre as economias dos países. Para Hirschman (2008), o investimento deve ser feito nos projetos que tenham o maior número de linkagens econômicas.
} 
Em tese, o agronegócio no Amapá se torna atrativo pela disponibilidade e baixo custo da terra, mão de obra barata, produtividade (duas safras de grãos/ano) e maiores vantagens competitivas quanto ao preço do frete em relação aos portos exportadores em operação no país. Tais condições inseriram o Amapá como parte integrante da estratégia do governo federal em implantar uma logística de transporte intermodal na Região Norte para escoar a produção agrícola nacional/regional e, com isso, reduzir o custo do frete para o mercado internacional.

Em 2019 a área plantada com grãos de soja no Amapá atingiu 20 mil hectares, com projeções de expansão para os próximos anos a uma taxa de $20 \%$ ao ano, diante de 400 mil hectares de potencial de plantio, conforme dados da Associação de Produtores de Soja - Amapá (APROSOJA-AP) (Gráfico 1).

\section{Gráfico 1 - Área plantada de soja no Amapá e projeções até 2022 (em hectares)}

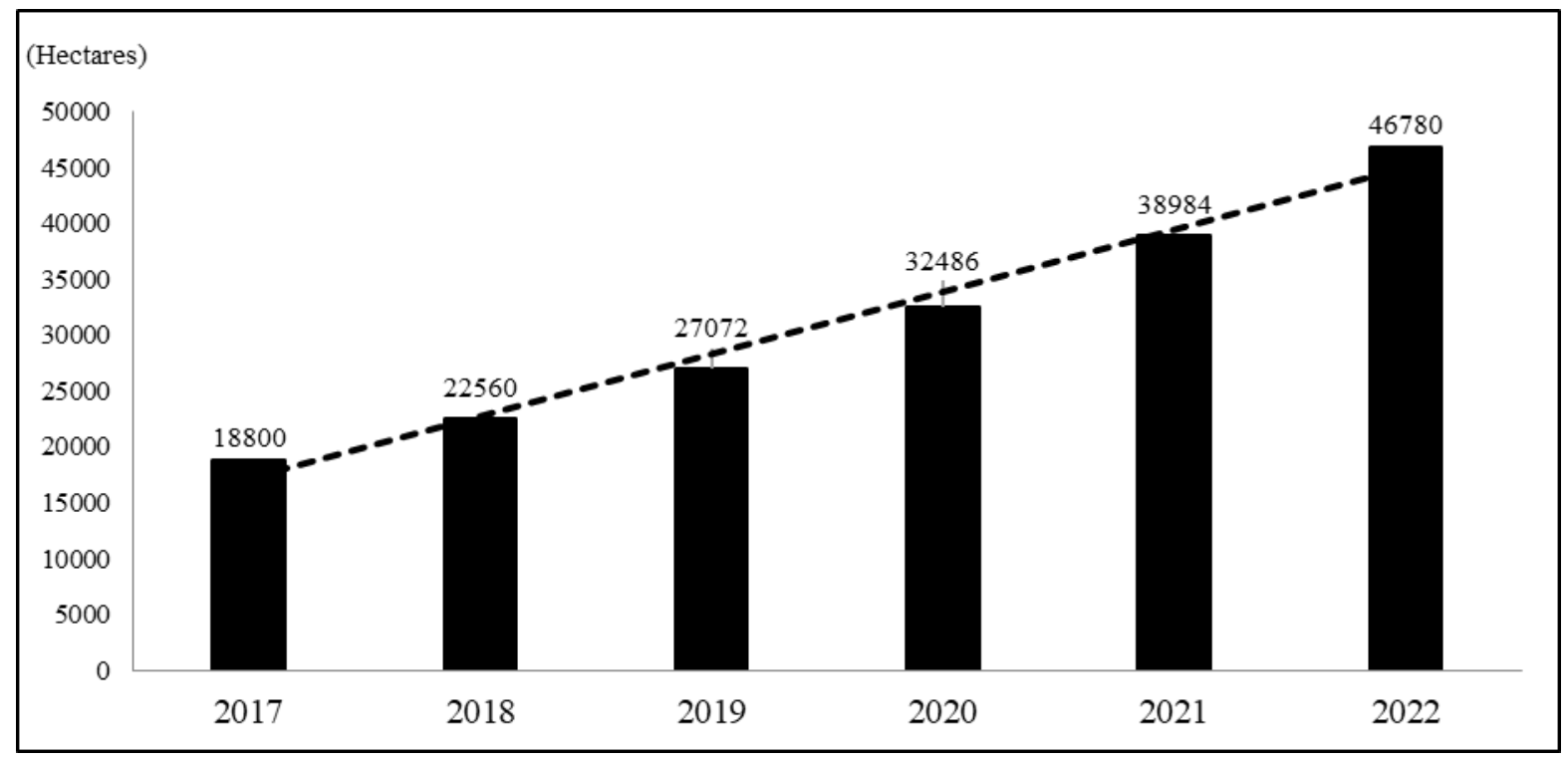

Fonte: APROSOJA-AP (2017).

Dados do Zoneamento Socioambiental do Cerrado do Amapá (ZSC-AP) indicam que uma área em torno de 200 mil hectares se enquadra como "zona de expansão produtiva em áreas com potencial para atividades agrícolas em diferentes níveis de mecanização" (IEPA, 2016, p. 34). Esses números frustram a expectativa expansionista de produtores de soja de chegar a 400 mil hectares de área de plantio ou de até 1.000.000 de hectares, na visão dos que vendem a ilusão do crescimento econômico a qualquer custo. 
Sobre esse aspecto, Castro (2007) analisa que o zoneamento se encontra consolidado em toda a Amazônia enquanto instrumento técnico de orientação ao ordenamento territorial, mas é desconsiderado na tomada de decisão política, além do que há diversas dimensões a considerar para garantir sua exequibilidade.

No caso do Amapá, insurgem-se no âmbito governamental propostas de estudos de zoneamento que possam se adequar à estratégia expansionista do agronegócio, sob a alegação de que os estudos elaborados pelo IEPA (2016) não consideraram a variável climática ou não cumpriram o receituário do Zoneamento Agrícola de Risco Climático (ZARC).

A explicação deste fato está nas diferenças metodológicas entre o zoneamento elaborado pelo IEPA (ZSC-AP) e o zoneamento agrícola (ZARC). Enquanto o primeiro foi elaborado segundo metodologia preconizada pelo Ministério do Meio Ambiente (MMA), o ZARC é um instrumento de política agrícola e gestão de riscos na agricultura, seguindo metodologia preconizada pelo Ministério da Agricultura, Pecuária e Abastecimento (MAPA).

"A nova fronteira da soja", como anunciado em várias mídias, parece intencionar desbancar o slogan de "estado mais preservador do país" e tudo indica que o modelo do agronegócio adotado no Amapá segue a mesma estratégia nacionalregional, viabilizando-se pela grilagem de terras públicas com conivência do Estado, pela negligência no cumprimento das normas ambientais e pelos crescentes conflitos agrários (CPT, 2016; TORRES; DOBLAS; ALARCON, 2017).

Entretanto, pode ser que a referida projeção não se concretize, a considerar a nova geração de produtores à frente do agronegócio, as modernas tecnologias, a verticalização local da cadeia e seus desdobramentos quanto às linkagens econômicas que possam beneficiar pequenos agricultores locais. Pesquisas sobre indicadores de qualidade de vida nos municípios produtores são recomendáveis para aferir os efeitos do agronegócio no Amapá.

A extração mineral, a construção de hidrelétricas, a exploração de petróleo e gás e o cultivo de soja representam as principais atividades econômicas que compõem a atual agenda governamental de desenvolvimento do Amapá, entendido como crescimento capaz de gerar emprego e renda. Historicamente, as lições aprendidas indicam que os efeitos econômicos positivos dessas atividades, principalmente as que apresentam rigidez locacional, são momentâneos (boom) e seguem situações de colapso quando da exaustão dos recursos, da queda de preço no mercado ou mesmo da finalização da etapa de construção das estruturas físicas de operação.

Os desdobramentos das atividades econômicas descritas são de difícil mediação pelo Estado e quase sempre impõem um acúmulo de passivos ambientais negligenciados ou invisibilizados quanto à responsabilização direta, ou, ainda, desfecham em ajustes de conduta com valoração mensurada em bases pouco 
justas ou insatisfatórias para as partes prejudicadas ou afetadas. Entretanto, reconhece-se que cabe ao Estado prover ajustes de regulação nas rendas da exploração de recursos naturais de modo a amenizar as desigualdades e os conflitos ecológicos distributivos (MARTÍNEZ ALIER, 2007).

\section{Áreas protegidas}

O Amapá apresenta um conjunto de áreas protegidas que mantém sob controle da União cerca de $70 \%$ da superfície territorial do Estado. Essas áreas foram criadas com a finalidade de preservação dos ecossistemas e de garantias territoriais de grupos indígenas, com possibilidades de uso sustentável de recursos naturais pelas comunidades tradicionais (Figura 2). 
Figura 2 - Áreas protegidas do Amapá

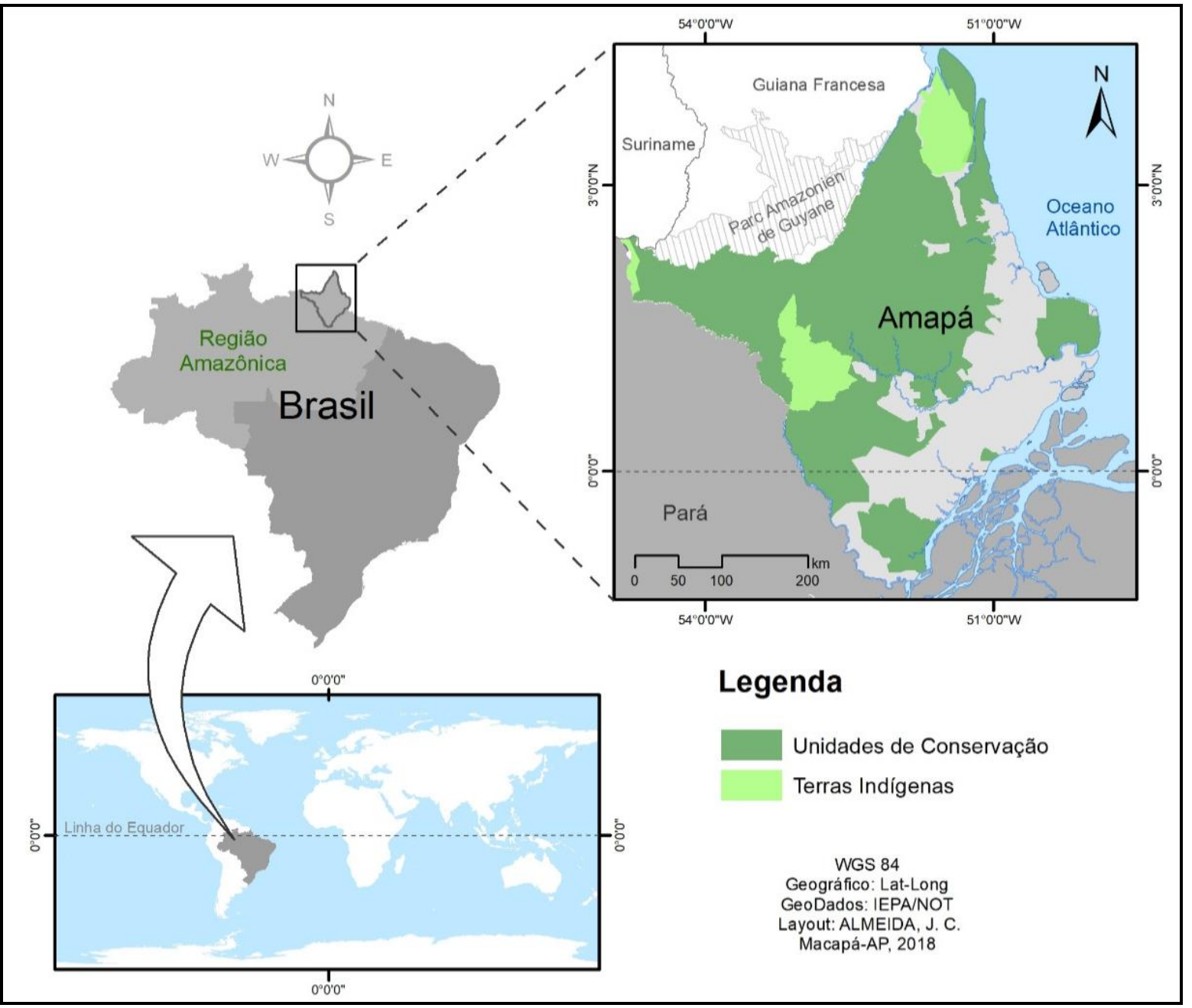

Fonte: Elaborado pelo geógrafo Jodson Almeida.

Becker (2001; 2004; 2005), denomina a região do Amapá como "fronteira da preservação", correlacionando-a a diversos interesses complementares, desde os afeitos a instituições não governamentais preservacionistas até aos vinculados à luta de populações tradicionais pelo direito à terra e aos recursos da floresta.

O cenário de preservação projetado por Becker se confirma pelo conjunto de áreas protegidas estabelecidas na região conhecida como Calha Norte do Rio Amazonas e Escudo das Guianas, que representam cerca de 20 milhões de hectares de territórios legalmente protegidos, constituindo um dos maiores blocos contínuos de ecossistema de floresta tropical protegido do planeta (Tabela 3). 
Tabela 3 - Áreas protegidas da Calha Norte do Rio Amazonas e Escudos das Guianas

\begin{tabular}{l|l|c}
\hline Região & Área Protegida & Hectares \\
\hline Amapá & Parque Nacional Montanhas do Tumucumaque & 3.865 .188 \\
\hline \multirow{4}{*}{ Pará } & Estação Ecológica do Grão-Pará & 4.245 .800 \\
\cline { 2 - 3 } & Floresta Estadual do Paru & 3.612 .900 \\
\cline { 2 - 3 } & Floresta Estadual do Trombetas & 3.172 .900 \\
\cline { 2 - 3 } & Reserva Biológica Maicuru & 1.151 .700 \\
\cline { 2 - 3 } & Floresta Estadual do Faro & 613.800 \\
\hline Guiana Francesa & Parque Natural Regional da Guiana & 3.390 .000 \\
\hline Total & & 20.052 .288 \\
\hline
\end{tabular}

Fonte: Organizado pelo autor (2019).

O conjunto de áreas protegidas do Amapá contempla a possibilidade de uso público associado à conservação da biodiversidade que pode ancorar um interessante debate sobre cenários de desenvolvimento regional. Irving (2006), por exemplo, faz considerações sobre uma possível cooperação binacional BrasilFrança para gestão dos parques nacionais transfronteiriços. A autora destaca as condições exóticas diferenciadas ("ou surreais") do potencial de ecoturismo nos parques da região, com propostas de circuitos integrados de valorização do patrimônio cultural e natural.

No Amapá, a presença de áreas protegidas (unidades de conservação, terras indígenas, quilombolas, áreas de preservação permanente e reserva legal), traz implicações diretas para a regularização de atividades extrativas de recursos naturais pelo mercado. Desde sempre, o binômio preservação/desenvolvimento tem pautado o debate político-ideológico no Amapá, com implicações que polarizam dois grupos rivais: os defensores da natureza intocada e os crédulos na economia de mercado.

Aqui emerge o problema do abandono do planejamento público que possa imaginar futuros alternativos para dar lugar ao impulso momentâneo dos interesses do mercado pela exploração ilimitada de riquezas naturais que, pelas lições apreendidas, tem colocado o Amapá em uma condição preocupante quanto aos problemas acumulados, como no caso da precariedade das condições de vida urbana. 


\section{A precariedade da urbe amapaense e a floresta}

A exploração in natura de recursos naturais no Amapá, sem agregação de valor local, não permitiu a estruturação de uma economia capaz de contrapor as mazelas de uma região de carências extremas e que se agravam na proporção direta das demandas de uma população que aumenta pela migração intrarregional e pela concentração urbana desordenada.

As relações sinergéticas entre as questões urbanas, a exploração dos recursos naturais e a preservação da biodiversidade são pouco investigadas em estudos regionais, embora haja hipóteses que tais categorias mantêm imbricações quanto a estudos prospectivos:

(...) o tema urbano é negligenciado na pesquisa e na política regional, submerso na onda verde que recobriu a preocupação sobre a Região. No máximo, mostram-se as carências das cidades "inchadas" que são, sem dúvidas, reais, mas constituem visão parcial, porque as obscurecem como força de desenvolvimento (BRASIL, 2009).

O papel da urbe, ainda que negligenciado pelas políticas públicas, torna-se o cerne para a construção de um projeto regional para a Amazônia, onde o maior desafio está em conciliar o desenvolvimento com a preservação das "florestas em pé", valorizando os serviços ecossistêmicos e garantindo seu manejo sustentável, defende Becker (2013).

No caso do estado do Amapá, o processo de urbanização desestruturado motiva reflexões que se contextualizam pela população de 669.526 habitantes (IBGE, 2010), com estimativas de 850 mil habitantes em 2019. Os núcleos urbanos concentram 99,3\% da população do Amapá, onde 20\% desse contingente constituem aglomerados subnormais nas duas principais cidades do estado, Macapá e Santana, consequência da rápida migração intrarregional das ilhas dos municípios paraenses próximos (TOSTES; SOUZA; FERREIRA, 2015; CHAGAS et al., 2016).

Entre os indicadores que desafiam a gestão estadual, as piores colocações do Amapá têm implicações diretas na qualidade de vida urbana e motivam atenção quanto às prioridades de políticas públicas (Tabela 4): 
Tabela 4 - Ranking com os piores indicadores que desafiam a gestão estadual no Amapá

\begin{tabular}{l|l|c|c}
\hline \multirow{2}{*}{ Área } & Indicadores & $\begin{array}{c}\text { Ranking } \\
2017\end{array}$ & $\begin{array}{c}\text { Variação de } \\
\text { posição na década }\end{array}$ \\
\hline \multirow{2}{*}{ Condições de Vida } & Saneamento adequado & $27^{\circ}$ & $27^{\circ}(2005-2015)$ \\
\cline { 2 - 4 } & Déficit habitacional & $25^{\circ}$ & $26^{\circ}(2007-2014)$ \\
\hline Infraestrutura - Energia & Qualidade energia & $27^{\circ}$ & $27^{\circ}(2005-2015)$ \\
\hline \multirow{2}{*}{$\begin{array}{l}\text { Infraestrutura - } \\
\text { Transporte }\end{array}$} & Proporção rodovias pavimentadas & $26^{\circ}$ & $27^{\circ}(2005-2015)$ \\
\cline { 2 - 4 } Educação & Qualidade rodovias & $25^{\circ}$ & $9^{\circ}(2006-2016)$ \\
\hline Saúde & IDEB - Ensino fundamental I & $26^{\circ}$ & $16^{\circ}(2005-2015)$ \\
\cline { 2 - 4 } & IDEB - Ensino fundamental II & $24^{\circ}$ & $9^{\circ}(2005-2015)$ \\
\hline Juventude & Mortalidade infantil & $26^{\circ}$ & $21^{\circ}(2005-2015)$ \\
\hline
\end{tabular}

Fonte: Macroplan (2017).

Entre os indicadores apresentados, chama atenção o saneamento inadequado, pois o Amapá parece negligenciar politicamente uma das mais importantes áreas que impactam a condição de vida urbana, a saúde da população e o meio ambiente. É possível que a precariedade de saneamento responda também pelos altos índices de mortalidade infantil que, associado às taxas de desocupação de jovens, acende a "luz amarela" quanto ao futuro do Amapá.

Sinal de atenção também para a queda livre do Amapá em educação, no ensino fundamental, que, associado ao desemprego, implica na necessidade de ações estruturantes de políticas sociais para além dos receituários reativos dos tradicionais dos Planos Plurianuais de Governo (PPAs).

A interpretação dos fenômenos urbanos e do desafio do pensamento prospectivo em torno das tensões do desenvolvimento dá sustentação ao paradigma de "produzir para conservar" (BECKER, 2001; 2004; 2013). O seu significado implica numa maior atenção às condições de vida urbana como fator determinante para a preservação da floresta, de modo a (re)credibilizar os princípios da sustentabilidade.

\section{Variáveis ou incertezas críticas dos cenários}

Diante das atividades econômicas apresentadas, a avaliação das variáveis (empregabilidade, impactos e riscos associados a conflitos distributivos) constitui as incertezas críticas que influenciam os cenários prospectados para o Amapá (Quadro 2). 


\section{Quadro 2 - Avaliação das variáveis associadas aos cenários do Amapá}

\begin{tabular}{|c|c|c|c|}
\hline Atividades & $\begin{array}{c}\text { Empregabilidade } \\
\text { direta }\end{array}$ & $\begin{array}{c}\text { Impactos e } \\
\text { riscos associados }\end{array}$ & Conflitos distributivos \\
\hline Mineração & $\begin{array}{l}\text { - Alta na } \\
\text { construção e na } \\
\text { operação (Entre } \\
2004 \text { e } 2016 \text { foram } \\
\text { gerados, em média, } \\
1.250 \text { empregos } \\
\text { diretos). }\end{array}$ & $\begin{array}{l}\text { - Significativos. } \\
\text { - Rompimento de } \\
\text { barragens e } \\
\text { inundações. } \\
\text { - Queda do preço } \\
\text { dos minérios } \\
\text { (condição } \\
\text { externa). }\end{array}$ & $\begin{array}{l}\text { - Com população em geral que } \\
\text { ressoam negativamente os } \\
\text { passivos ambientais e sociais } \\
\text { acumulados pela mineração. } \\
\text { - Com populações locais pela } \\
\text { ausência de processos } \\
\text { participativos e transparência na } \\
\text { aplicação da Compensação } \\
\text { Financeira pela Exploração de } \\
\text { Recursos Minerais (CFEM). }\end{array}$ \\
\hline Hidrelétricas & $\begin{array}{l}\text { - Alta na } \\
\text { construção e baixa } \\
\text { na operação (Entre } \\
2010 \text { e } 2014 \text { foram } \\
\text { gerados, em média, } \\
\text { 1.000 empregos } \\
\text { diretos pela construção } \\
\text { das hidrelétricas } \\
\text { Ferreira Gomes e } \\
\text { Cachoeira Caldeirão, } \\
\text { no Rio Araguari). }\end{array}$ & $\begin{array}{l}\text { - Significativos. } \\
\text { - Rompimento de } \\
\text { barragens e } \\
\text { inundações. }\end{array}$ & $\begin{array}{l}\text { - Com pescadores e ribeirinhos } \\
\text { pela diminuição dos estoques } \\
\text { pesqueiros. } \\
\text { - Com moradores afetados por } \\
\text { inundações. } \\
\text { - Com populações locais pela } \\
\text { ausência de processos } \\
\text { participativos e transparência na } \\
\text { aplicação da Compensação } \\
\text { Financeira pela Utilização de } \\
\text { Recursos Hídricos (CFURH). }\end{array}$ \\
\hline Petróleo & $\begin{array}{l}\text { - Baixa na } \\
\text { exploração e ainda } \\
\text { indefinida na } \\
\text { produção. }\end{array}$ & $\begin{array}{l}\text { - Pouco } \\
\text { significativos na } \\
\text { fase de exploração } \\
\text { (pesquisa) e } \\
\text { significativos na } \\
\text { produção. } \\
\text { - Queda do preço } \\
\text { do barril do } \\
\text { petróleo (condição } \\
\text { externa). }\end{array}$ & $\begin{array}{l}\text { - Com grupos sociais que } \\
\text { defendem e dependem da } \\
\text { natureza em relação aos corais e } \\
\text { às áreas protegidas. } \\
\text { - Com pescadores pelas limitações } \\
\text { das áreas de pesca. } \\
\text { - Com população em geral pela } \\
\text { ausência de processos } \\
\text { participativos e transparência na } \\
\text { aplicação dos Royalties. }\end{array}$ \\
\hline Agronegócio & $\begin{array}{l}\text { - Estimada (A } \\
\text { APROSOJA estima } \\
\text { em } 32.000 \text { empregos } \\
\text { diretos a serem } \\
\text { gerados). }\end{array}$ & $\begin{array}{l}\text { - Não avaliados ou } \\
\text { avaliados de forma } \\
\text { simplificada (o } \\
\text { Amapá adota a } \\
\text { Licença Ambiental } \\
\text { Única (LAU) }{ }^{3} \text {. } \\
\text { - Queda do preço }\end{array}$ & $\begin{array}{l}\text { - Com comunidades rurais, } \\
\text { Comissão Pastoral da Terra } \\
\text { (CPT) e organizações da } \\
\text { sociedade civil por possível } \\
\text { grilagem de terras e impactos } \\
\text { ambientais (uso de agrotóxicos). }\end{array}$ \\
\hline
\end{tabular}

\footnotetext{
3 O Ministério Público Federal ingressou no Supremo Tribunal Federal com Ação Direta de Inconstitucionalidade em desfavor da Licença Ambiental Única do Amapá (ADI 5475).
} 


\begin{tabular}{|l|l|l|l|}
\hline & & $\begin{array}{l}\text { da soja (condição } \\
\text { externa). }\end{array}$ & \\
\hline & - Com potencial & - Insignificante. & - Com indígenas, populações \\
(em referência ao & - Ausência de \\
políticas públicas. & Aiante de ameaças pelo Estado de \\
Áreas & uso público). & $\begin{array}{l}\text { redução de limites, paralização de } \\
\text { demarcação ou permissão de } \\
\text { exploração de recursos naturais. }\end{array}$ \\
\hline
\end{tabular}

Fonte: Elaborado pelo autor (2019).

A sinalização de que o setor do agronegócio pode gerar 32.000 empregos diretos demanda cautela e verificação criteriosa dos dados apresentados pela Aprosoja (2017). Sabe-se que a atividade é mecanizada no plantio e na colheita, remetendo a possibilidades de empregabilidade fora da cadeia de produção de grãos. Isso requer políticas públicas de longo prazo e controle social para não se tornar moeda de troca entre a geração de emprego e a apropriação de terras sem respeito às regras da reforma agrária e ao meio ambiente. A problematização das metamorfoses do mercado de trabalho e da geração de emprego por grandes projetos na Amazônia é tema recorrente em vários estudos que sinalizam a difícil convivência entre população amazônica e capitalismo (CASTRO, 1994; 1999, 2012; CARDOSO; MÜLLER, 2008; LOUREIRO, 2012; SOUZA, 2019).

Os cenários esboçados a seguir são sintéticos, não significando, entretanto, que não permitam profundas reflexões, concordantes e discordantes, quanto aos futuros previsíveis.

\section{Cenário trágico}

Caracterizado pela continuidade da exportação de commodities sem processos de industrialização local (sem linkagens econômicas); poucos empregos diretos gerados e/ou empregos temporários; aumento do desmatamento da floresta e da pressão sobre as áreas protegidas; impactos não mitigados ou ocultos pelas fragilidades das políticas ambientais; conflitos ecológicos distributivos crescentes, quase sempre mediados judicialmente; estrutura pública de serviços básicos em colapso; desemprego e violência crescentes nos núcleos urbanos.

Referida condição traduz o legado de um modelo de desenvolvimento que, a expensas da liberalidade de exploração ilimitada da base natural, foi imposto e perdurou por muito tempo como a única alternativa regional. Tal como toda a Amazônia brasileira, também o estado do Amapá ainda conserva parte dessa trágica opção de desenvolvimento, onde a relação custo/benefício quase sempre passou ao largo das preocupações governamentais, resultando em desigualdades 
sociais e em passivos ambientais que se manifestam em conflitos cíclicos e/ou permanentes, ou, então, como casos de reparação/compensação que se arrastam pelas contendas judiciais.

Nessa condição, o futuro fica delimitado pelo curso dos acontecimentos segundo "janelas de oportunidades" aferidas pela melhor conveniência dos agentes do mercado. A ausência de ações programáticas em torno da agregação de valor ao produto natural se faz sentir nos mais diversos campos da gestão pública, impactando negativamente, em primeiro lugar, na capacidade de geração de tributos por não encontrar sustentação na base produtiva instalada.

Adicionalmente, nos casos de projetos onde a oferta de trabalho temporário para a fase de implantação mobiliza grandes contingentes humanos, oriundos dos mais diversos rincões, nas fases seguintes provoca um incremento populacional que impacta diretamente as regiões envolvidas. Pelas dificuldades circunstanciais de partes desses contingentes retornarem às suas regiões de origem, se decorre o crescente inchaço das periferias urbanas, multiplicando a formação de aglomerados humanos em condição de vida subnormal e também a precarização do atendimento dos serviços públicos básicos.

Os ciclos da mineração e da construção das hidrelétricas são exemplos da conjuntura que, ao mesmo tempo, colocou o Amapá no ranking mediano das taxas de desocupação entre os entes federados, atingindo entre 2012 e 2016 taxas de $12 \%$ e atualmente o faz permanecer, desde 2017 , com uma das maiores taxas de desocupação do país, em torno de 20\% (IBGE, 2018).

O mercado de trabalho no Amapá é urbano, constituído por uma mão de obra pouco qualificada e pobre. A falta de oportunidades de trabalho e de geração de renda constitui uma das grandes causas da violência e da criminalidade, pelo menos, do agravamento desta, a ponto de colocar o sistema de segurança pública e de assistência social do estado em alerta, com ações reativas em detrimento de preventivas.

Frente a um previsível quadro com o contorno citado, é de se esperar que as carências para investimentos do próprio Estado sejam compensadas pela dependência de arranjos políticos que, por serem imediatistas, acabam priorizando ações de caráter circunstanciais. Igual correspondência também se reproduz com a gestão dos recursos naturais e das áreas protegidas que, na ausência de políticas públicas para melhor aparelhamento estatal, continuará com rotinas de pouca repercussão e que não conseguem se contrapor às frentes de ocupação pioneira, tampouco ao poder de convencimento dos projetos induzidos unicamente pelo mercado para a exploração de recursos naturais.

\section{Cenário tradicional}


Neste cenário as atividades econômicas oscilam quanto à internalização de benefícios diretos, como geração de emprego e arrecadação de tributos; as áreas protegidas mantêm gestão deficitária (apenas no papel); os impactos identificados em estudos ambientais não são mitigados pela negligência na condução das políticas ambientais; os conflitos ecológicos distributivos são recorrentes; há aumento da pressão sobre a estrutura pública de serviços básicos; cresce o desemprego e a violência nos núcleos urbanos. Cenário vinculado aos Planos Plurianuais de Governos (PPAs).

Referido cenário, embora projete uma relação futura, não deixa de ter aderência com a realidade do estado, onde a trajetória de quase 30 anos de autonomia político-administrativa ainda não conseguiu se libertar das amarras de um sistema federativo centralizador e de um modelo de desenvolvimento ditado pela dependência de um ex-território federal. A desejável condição libertária para transformar vantagens competitivas do Amapá em reais vetores de desenvolvimento socioeconômico equânimes está sempre vinculada às externalidades que, por depender de outras variáveis, acaba dando curso ao continuísmo com poucas expectativas de mudanças.

A previsão de futuro tradicionalista dá lugar à manutenção de um Estado com seus limites e deficiências que não conseguem se opor aos problemas existentes, tendendo à precarização crescente da qualidade de vida da população. Nesse contexto, é razoável admitir que o imobilismo do Estado na proposição de caminhos mais promissores para o desenvolvimento regional também acena, como situação de risco, para a própria condição de vida da população.

A impossibilidade para alavancar a economia estadual para além das commodities resulta no aumento das dificuldades para o atendimento das necessidades da sociedade. Quando isso é avaliado frente à crescente concentração populacional urbana, com suas consequências óbvias por maiores assistências sociais, não há como negar que o resultado será sempre a precarização dos serviços públicos básicos. Também é de se esperar que as dificuldades de investimento do Estado, não possibilitando a ampliação de programas e oportunidades mais vigorosas para o atendimento da juventude, sejam uma das razões a responder pela acentuação da violência que em sua base vem sendo alicerçada pela vulnerabilidade do jovem ao uso das drogas ilícitas e outros crimes.

No plano ambiental, a manutenção da capacidade operacional das estruturas de comando e controle em níveis não satisfatórios para fazer frente às exigências que decorrem de grandes projetos de exploração de recursos naturais precisará ser admitida em suas limitações e consequências para a gestão do patrimônio natural do estado. O risco de continuar dando curso ao funcionamento dos instrumentos tradicionais de gestão, resumidamente como cumprimento burocrático, desconectados de uma efetiva política ambiental de Estado, contradiz inteiramente com as aspirações gerais assentadas no apelo do "estado mais preservado do país". 
No presente cenário, a menção ao PPA como instrumento de planejamento estadual meramente protocolar se consolida distante de processos democráticos participativos, pois, a continuar as práticas vigentes, percebe-se que a cada edição, por estar mais preocupada com a forma legal ritualística do que propriamente com as soluções dos problemas existentes, acaba se tornando peça figurativa, onde as práticas acontecem segundo as conveniências circunstanciais do poder político.

\section{Cenário sustentável}

Motivado pelo incremento de processos de industrialização dos recursos naturais localmente, em diferentes escalas, com linkagens diretas e indiretas, dinamizando a economia e gerando empregos crescentes; uso público das áreas protegidas assumido como política de Estado; impactos ambientais significativos controlados, mitigados ou compensados. Conflitos distributivos fortalecendo a democracia participativa e comunitária; estrutura pública de serviços básicos redimensionada; diminuição do desemprego e da violência nos núcleos urbanos. Cenário requer ruptura e planejamento estratégico.

Referida projeção para o Amapá também poderia ser chamada de "cenário utópico", onde os problemas e limitações passariam a ser supridos com soluções alternativas ou de maior permanência, centradas na qualidade de vida da população e no uso sustentável dos recursos naturais. Para isso, será preciso que, em primeiro lugar, seja enfrentado o desafio de superar a contradição conceitual "desenvolvimento-meio ambiente", articulando, em termos teóricos e práticos, essas dimensões concretamente no território.

Isso significa que a partir de políticas de desenvolvimento baseadas na sustentabilidade e potencialidades ambientais e sociais seja possível delinear caminhos voltados à verticalização e organização do processo produtivo, de modo a promover oportunidades de trabalho e renda. Nessas condições, as atividades econômicas: mineração, hidrelétrica, petróleo, agronegócio e áreas protegidas, vistas como fatores relevantes para o desenvolvimento do estado, devem encontrar um ambiente de entendimento com outras alternativas econômicas, onde a sustentabilidade seja a premissa básica para identificar potencialidades e limitações. Os recursos naturais devem ser utilizados considerando-se os impactos diretos e indiretos para a sociedade e para a natureza, aliados à antevisão de escassez relativa como limite para regular as opções presentes e futuras de ocupação do território e de uso dos recursos.

Para isso, será necessário abrir uma discussão para reestruturar as ações do PPA, de modo a evitar que as ações propostas não se resumam aos interesses específicos das instituições públicas/privadas envolvidas, sem participação da sociedade e sem vínculo com os objetivos estratégicos de Estado. Isso, em 
primeiro lugar, impactará na distribuição dos recursos orçamentários, que, em vez de se guiar apenas pela lógica economicista do planejamento estatal, deverá priorizar o atendimento das demandas sociais da população a partir de processos mais democráticos e de longo prazo.

Em um futuro de maiores oportunidades promovido por relações sociais e políticas econômicas sustentáveis, o primeiro setor a ser impactado positivamente será o mercado interno, ampliando o seu potencial de inclusão via elevação da oferta de emprego e renda. De igual modo, a possibilidade de mobilizar maior captação de tributos também favorece ao sistema financeiro do Estado, permitindo-lhe estabelecer políticas sociais de médio e longo prazo, priorizando ações que levem ao equacionamento dos conflitos distributivos e à diminuição das desigualdades. No plano das estruturas funcionais do Estado, o redimensionamento e reorganização das bases institucionais, no sentido de melhor amparar o paradigma da sustentabilidade, apresentam-se como condição essencial para garantir que os direitos sociais da população estejam sempre a pontuar as decisões governamentais.

Na previsão da sustentabilidade, o esperado é que o estado possa ampliar suas exportações e, ao mesmo tempo, aprofundar a integração de sua estrutura produtiva, incorporando novas tecnologias e elevando os níveis de produtividade. Pela maior dinamização do mercado interno e da estrutura ocupacional, se permitirá maior eficácia às políticas de estímulo à economia solidária, informal, de perfil não capitalista, mais voltadas ao atendimento interno em pequena/média escala. O problema da violência urbana passa a ser concretamente combatido por meio de políticas de segurança pública e assistência social, que articulam ações de prevenção e expansão da cidadania.

\section{Considerações Finais}

Em concordância com o entendimento geral dos estudiosos de cenários prospectivos, admite-se que, embora não seja possível predizer o futuro, é relevante buscar fazê-lo, de modo a contribuir com o balizamento do acelerado crescimento das incertezas e das mudanças paradigmáticas que caracterizam a entrada no Século XXI. Nessa perspectiva, o presente artigo, voltado a perscrutar o futuro do estado do Amapá, enquadra-se inteiramente à regra dos referidos estudos, ao considerar que, na melhor hipótese de acertos, a realidade será sempre mais complexa do que tudo aquilo que fora possível predizer a partir da condição presente.

Com essa reflexão, conclui-se que, primeiramente, o esforço para aproximar o presente do campo das inquietações sobre o futuro do estado, considerando que o estágio de desenvolvimento do Amapá é marcado pela recente autonomia político- 
administrativa, pela forte atuação preservacionista e pela presença de projetos exploratórios de recursos naturais com poucos significados para $\mathrm{O}$ desenvolvimento includente e solidário. A par dessa realidade, as atividades econômicas de mineração, hidrelétrica, petróleo, agronegócio e áreas protegidas conformaram o ambiente de análise das tendências do estado, na possibilidade de verificar a maior ou menor efetividade destas a partir dos cenários: trágico, tradicional e sustentável.

Como era de se esperar, as deficiências e respectivas consequências relacionadas aos cenários trágico e tradicional, atuando em maior ou menor grau sobre as condições de vida da população e da gestão dos recursos naturais, tendem a demonstrar um futuro pessimista ou de poucas expectativas para o desenvolvimento do estado, por estarem assentadas em resquícios de práticas públicas e privadas pouco atentas aos requerimentos gerais da sociedade.

No cenário sustentável, antevisto como condição desejável, vislumbra-se, utopicamente, a possibilidade de acontecimentos que tendam a impactar diretamente o aperfeiçoamento da gestão pública e a agregação de valor à exploração de recursos naturais. Consequências plausíveis dessas situações, sinteticamente, manifestar-se-ão na melhoria da captação de tributos e da capacidade de investimento do Estado, na oferta de maiores oportunidades de trabalho e renda à população e, de modo reconhecível, com mudanças de posturas ante ao valor do bem natural, na formulação de mecanismos que garantam o controle mais efetivo dos recursos pela sociedade.

A projeção de cenário trágico a tradicional para o Amapá possibilita (re)credibilizar o ordenamento territorial e a regularização fundiária como estratégias de reversão do pior cenário para algo mais otimista. Entretanto, referida possibilidade também mantém correlação com a radicalidade de processos mais democráticos de participação, emancipatórios, de longo prazo, no sentido de refutar o discurso ainda dominante de que o desenvolvimento se dá apenas pelo imperativo da regulação social neoliberal em favor de uma economia extrativa.

\section{Referências}

AECOM do Brasil. Relatório de Impacto Ambiental: perfuração marítima nos blocos FZA-M-57, FZA-M-86, FZA-M-88, FZA-M-125 e FZA-M-127 - Bacia da Foz do Amazonas. Rio de Janeiro: AECOM do Brasil; Total E\&P do Brasil, 2015a.

AECOM do Brasil. Relatório de Impacto Ambiental: atividade de perfuração marítima no bloco FZA-M-59, na bacia da Foz do Amazonas. Rio de Janeiro: AECOM do Brasil; BP Energy do Brasil, 2015b. 
AECOM do Brasil. Relatório de Impacto Ambiental: atividade de perfuração marítima no Bloco FZA-M-90, na Bacia da Foz do Amazonas. Rio de Janeiro: AECOM do Brasil; Queiroz Galvão Exploração e Produção, 2015c.

ANP - AGÊNCIA NACIONAL DE PETRÓLEO, GÁS NATURAL E BIOCOMBUSTÍVEIS. 11a Rodada de Licitações de Blocos. Disponível em: http:/ / rodadas.anp.gov.br/pt/concessao-de-blocos-exploratorios-1/11-rodadade-licitacao-de-blocos. Acesso em: 20 set. 2018.

APROSOJA - ASSOCIAÇÃO BRASILEIRA DOS PRODUTORES DE SOJA. O Agronegócio no Amapá. Material de apresentação em PowerPoint, APROSOJA-AP, junho 2017.

BECKER, B. K. A urbe amazônida: a floresta e a cidade. Rio de Janeiro: Garamond, 2013.

BECKER, B. K. Geopolítica da Amazônia. Estudos Avançados, 19 (53), 2005, p. 71-86. Disponível em: http://www.scielo.br/pdf/ea/v19n53/24081.pdf.

Acesso em: 20 set. 2018.

BECKER, B. K. Amazônia: geopolítica na virada do III milênio. Rio de Janeiro: Garamond. 2004.

BECKER, B. K. Revisão das políticas de ocupação da Amazônia: é possível identificar modelos para projetar cenários? Parcerias Estratégicas, n. 12, set. 2001. Disponível em: http://seer.cgee.org.br/index.php/parcerias_estrategicas/article/viewFile/178/17 2. Acesso em: 07 set. 2018.

BECKER, B. K.; MIRANDA, M.; MACHADO, L. O. Fronteira amazônica: questões sobre a gestão do território. Brasília/Rio de Janeiro: Editora UnB/Editora UFRJ, 1990.

BECKER, B. K.; STENNER, C. Um futuro para a Amazônia. São Paulo: Oficina de Textos, 2008.

BRASIL. Centrais Elétricas do Norte do Brasil. Cenários Socioenergéticos da Amazônia 2000-2020. Brasília, 2001. 
BRASIL. Centrais Elétricas do Norte do Brasil. Estudos de Inventário Hidrelétrico da Bacia Hidrográfica do Rio Araguari, Estado do Amapá, 1999.

BRASIL. Ministério das Minas e Energia. Plano Decenal de Expansão de Energia 2024. Empresa de Pesquisa Energética. Brasília, 2015.

BRASIL. Ministério de Ciência e Tecnologia. Centro de Gestão e Estudos Estratégicos. Um projeto para a Amazônia no século 21: desafios e contribuições. Brasília, 2009.

BRASIL. Ministério do Meio Ambiente. Programa Amazônia Sustentável. Resumo Executivo. Brasília, 2006.

BRASIL. Ministério do Meio Ambiente. Política Nacional Integrada para a Amazônia Legal. Brasília, 1995.

BRONDÍZIO, L. S. Gestão de recursos pesqueiros no âmbito do Programa de Desenvolvimento Sustentável do Amapá. 2003. Dissertação (Mestrado) Programa de Pós-Graduação em Ciências Ambientais, Universidade de São Paulo, São Paulo, 2003.

BUARQUE, S. C. Metodologias e técnicas de construção de cenários globais e regionais. Texto para Discussão, n. 939. Brasília: IPEA, 2003.

BUNKER, S. G. Da castanha-do-pará ao ferro: os múltiplos impactos dos projetos de mineração na Amazônia brasileira. Novos Cadernos NAEA, v. 6, n. 2, dez. 2003, p. 5-38.

BUNKER, S. G. Underdeveloping the Amazon: extraction, unequal exchange and the failure of the modern State. Chicago, University of Chicago Press, 1988.

CARDOSO, F. H.; MÜLLER, G. Amazônia: expansão do capitalismo. Rio de Janeiro: Centro Edelstein de Pesquisas Sociais, 2008. Disponível em: http://books.scielo.org/id/mnx6g/pdf/cardoso-9788599662731.pdf. Acesso em: 29 set. 2018.

CASTRO, E. Políticas de ordenamento territorial, desmatamento e dinâmicas de fronteira. Novos Cadernos NAEA, Belém, v. 10, n. 2, 2007, p. 105-126.

CASTRO, E. Tradição e modernidade: a propósito de processos de trabalho na Amazônia. Novos Cadernos NAEA, v. 2, n. 1, dez. 1999. 
CASTRO, E. Industrialização, transformações sociais e mercado de trabalho. Papers do NAEA, Belém, n. 23, mai. 1994.

CASTRO, M. C. Desenvolvimento sustentável e gestão ambiental na formulação de políticas públicas: a experiência do Estado do Amapá. Macapá: CEFORH, SEMA, 1998.

CHAGAS, M. A. Amapá: a mineração e o discurso da sustentabilidade: de Augusto Antunes a Eike Batista. Rio de Janeiro: Garamond, 2013.

CHAGAS, M. A (Org.). Sustentabilidade e gestão ambiental no Amapá. Macapá: SEMA, 2002.

CHAGAS, M. A.; FILOCREÃO, A. S. M.; RABELO, B. V.; FERNANDES, A. $\mathrm{V}$. A articulação entre o complexo verde de Ab'Saber e o complexo urbano de Becker como desafio do desenvolvimento regional: Amapá como um caso amazônico. Revista Brasileira de Pós-Graduação, v. 13, n. 32, 2016.

COELHO, M. C. N.; MONTEIRO, M. A. As economias extrativas e o subdesenvolvimento da Amazônia brasileira: contribuições do Prof. Stephen Bunker. Novos Cadernos NAEA, v. 8, n. 1, jun. 2005, p. 5-17.

COSTA, H. A.; NASCIMENTO, E. Cenários para o turismo no Brasil 2007-2010: análise da consistência metodológica e plausibilidade dos cenários. Caderno Virtual de Turismo, v. 7, n. 3, 2007.

CPT - COMISSÃO PASTORAL DA TERRA. Conflitos no campo: Brasil 2016. Goiânia: CPT Nacional, 2016.

DRUMMOND, J. A. Natureza rica, povos pobres? Questões conceituais e analíticas sobre o papel dos recursos naturais na prosperidade contemporânea. Ambiente \& Sociedade, n. 10, 1 sem. 2002. Disponível em: http://www.scielo.br/pdf/asoc/n10/16885.pdf. Acesso em: 15 ago. 2018.

DRUMmOND, J. A.; PEREIRA, M. A. P. O Amapá nos tempos do manganês: Um estudo sobre o desenvolvimento de um estado amazônico 1943-2000. Rio de Janeiro: Garamond, 2007. 
ENRÍQUEZ, M. A. Mineração: maldição ou dádiva? Os dilemas do desenvolvimento sustentável a partir de uma base mineira. São Paulo: Signus Editora, 2008.

EPE - EMPRESA DE PESQUISA ENERGÉTICA. Estudo de Inventário Hidrelétrico da Bacia Hidrográfica do Rio Jari, entre os Estados do Pará e Amapá. Rio de Janeiro: EPE, 2010.

GODET, M.; DURANCE, P. A prospectiva estratégica: para as empresas e os territórios. UNESCO: Editora DUNOD, 2011. Disponível em: http://es.laprospective.fr/dyn/traductions/contents/findunod-godet-duranceext-vpt.pdf. Acesso em: 02 jun. 2018.

HIRSCHMAN, A. O. Desenvolvimento por efeitos em cadeia: uma abordagem generalizada. In: SORJ, B.; CARDOSO, F. H.; FONT, M. (org.). Economia e movimentos sociais na América Latina [online]. Rio de Janeiro: Centro Edelstein de Pesquisa Social, 2008, p. 21-64. Disponível em: http://books.scielo.org/id/rjfv9/pdf/sorj-9788599662595.pdf. Acesso em: 02 jun. 2018.

IBGE - INSTITUTO BRASILEIRO DE GEOGRAFIA E ESTATÍSTICA. Taxa de Desocupação do Amapá. Tabela de Resultados. IBGE, PNAD. Disponível em: https://ww2.ibge.gov.br/home/estatistica/indicadores/trabalhoerendimento/pna d_continua/default_novos_indicadores.shtm. Acesso em: 10 out. 2018.

IBGE - INSTITUTO BRASILEIRO DE GEOGRAFIA E ESTATÍSTICA. População do Amapá [Censo 2010; estimada para 2018]. Disponível em: https://cidades.ibge.gov.br/brasil/ap/panorama. Acesso em: 04 out. 2018.

IEPA - INSTITUTO DE PESQUISAS CIENTÍFICAS E TECNOLÓGICAS DO ESTADO DO AMAPÁ. Zoneamento socioambiental do Cerrado do Estado do Amapá. Macapá: IEPA; EMBRAPA, 2016.

IRVING, M. A. Áreas Protegidas de fronteira e turismo sustentável na Amazônia: entre o surrealismo e a invenção. Revista de Desenvolvimento Econômico, VIII, n. 13, 2006.

LOUREIRO, V. R. A Amazônia no século 21: novas formas de desenvolvimento. Revista Direito GV, vol. 8, n. 2, São Paulo, jul./dez. 2012. 
MACROPLAN. Desafios da gestão estadual. 3. ed. Rio de Janeiro, 2017. Disponível em: https://www.desafiosdosestados.com/. Acesso em: 13 set. 2018.

MARCIAL, E. C.; GRUMBACH, R. J. S. Cenários prospectivos: como construir um futuro melhor. 5. ed. rev. e ampl. Rio de Janeiro: Editora FGV, 2008.

MARTÍNEZ ALIER, J. O ecologismo dos pobres: conflitos ambientais e linguagens de valoração. São Paulo: Contexto, 2007.

MONTEIRO, M. A. ICOMI no Amapá: meio século de exploração mineral. Novos Cadernos NAEA, v. 6, n. 2, dez. 2003, p. 113-168.

MONTEIRO, M. A. Mineração e metalurgia na Amazônia: contribuição à crítica da ecologia política à valorização de recursos minerais da região. 2001. Tese (Doutorado) - Núcleo de Altos Estudos Amazônicos, Universidade Federal do Pará, Belém, 2001.

MONTEIRO, M. A.; COELHO, M. C. N. Mineração e entropia: notas sobre interação com processos de desenvolvimento. Novos Cadernos NAEA, v. 10, n. 1, jun. 2007, p. 23-44.

MOULIN, N. Amapá: um norte para o Brasil. São Paulo: Cortez Editora, 2000.

OLIVEIRA, M. J. Mineração e desenvolvimento local: benefícios e desafios aos municípios amapaenses. 2010. Tese (Doutorado) - Núcleo de Altos Estudos Amazônicos, Universidade Federal do Pará, Belém, 2010.

POLANYI, K. A grande transformação: as origens da nossa época. 2. ed. Rio de Janeiro: Campus, 2000.

RUELLAN, A.; CASTRO, M.; MOULIN, N. (org.). Desenvolvimento sustentável no Amapá: uma visão crítica. Brasília: Fundação João Mangabeira, 2007.

SACHS, I. Desenvolvimento includente, sustentável e sustentado. Rio de Janeiro: Garamond, 2004. 
SANTOS, B. S.; MENESES, M. P. (Org.). Epistemologia do Sul. 2. ed. Coimbra: Almedina, Universidade de Coimbra, CES, 2010.

SOUZA, M. História da Amazônia: do período pré-colombiano aos desafios do século XXI. Rio de Janeiro: Record, 2019.

TORRES, M.; DOBLAS, J.; ALARCON, D. F. “Dono é quem desmata”: conexões entre grilagem e desmatamento no Sudoeste paraense. São

Paulo/Altamira: Urutu-branco/Instituto Agronômico da Amazônia, 2017.

Disponível em: http://www.pdrsxingu.org.br/publicacao.aspx?n=40. Acesso em: 03 out. 2018.

TOSTES, J. A.; SOUZA, A. C. M.; FERREIRA, J. F. C. O desenvolvimento local integrado entre as cidades de Macapá e Santana (Estado do Amapá, Brasil).

Revista PRACS, v. 8, n. 2, 2015.

VEIGA, J. E. Desenvolvimento sustentável: o desafio do século XXI. Rio de Janeiro: Garamond, 2005.

VIEIRA, I. C. G.; TOLEDO, P. M.; ROCHA, G. M.; SANTOS JÚNIOR, R. A. O. Bertha Becker e a Amazônia. Revista Bibliográfica de Geografía y Ciencias Sociales, v. XIX, n. 1103 (4), 2014. Disponível em: http://www.ub.edu/geocrit/b3w-1103-4.htm. Acesso em: 13 jul. 2018.

Endereço para correspondência:

Marco Antonio Chagas - marco.chagas@uol.com.br Rodovia Juscelino Kubitschek, km 2 - Jardim Marco Zero 68903-419 Macapá/AP, Brasil

Antônio Sérgio Monteiro Filocreão - afilocreao@gmail.com Rodovia Juscelino Kubitschek, km 2 - Jardim Marco Zero 68903-419 Macapá/AP, Brasil 
Marco Antonio Chagas e Antônio Sérgio Monteiro Filocreão

86 | Revista Brasileira de Desenvolvimento Regional, Blumenau, 7 (3), P. 53-86, 2019 